\title{
Editorial
}

\section{Participating in peer review is both a privilege and a professional duty}

As Editor-in-Chief, authors communicate with me on many matters. One common query is along the lines of 'Why is it taking you so long to give me the decision on my manuscript?'. The most common response is that 'I am still waiting for the reviewers' comments'. Most authors cannot believe this, anticipating that their manuscript is so interesting that, not only would any potential reviewer agree to look at it, but that they would read it and write a report on it within days. This is, quite simply, not the case. Authors may be surprised to know that it is common for us to need to ask as many as ten, and sometimes even more than ten, potential reviewers before we get the agreement of two of them to look at a manuscript. Even then, we may not get two reviews in good time, or even at all. I would like to take this opportunity, first, to tell readers about the stages that lead up to making a decision on a manuscript submitted to the British Journal of Nutrition from the time of receipt of the manuscript, and, secondly, to provide some insight into the enormity of the task of peer review across the discipline of nutritional science and to make a plea for those who feel qualified to participate in this task to do so.

Manuscripts are submitted to the $B J N$ electronically; they are received by the $B J N$ editorial office. Staff in the office run a quality-control check on the manuscript, checking such things as the format, and the inclusions of authors' contributions, conflict of interest and, where appropriate, ethical approval statements. The staff also assign the manuscript to a member of the Editorial Board and to myself or one of the Deputy Editors who will eventually make a decision on the manuscript. These processes require staff to read the manuscript and, quite rightly, must be carried out thoroughly. Since each member of staff is dealing with several manuscripts at any one time (last year the $B J N$ received almost four manuscripts every working day), as well as engaging in other activities related to the running of the $B J N$ and its three sister journals, it typically takes a few days to deal with this initial phase of handling a manuscript. Once the manuscript has been assigned to a member of the Editorial Board, that person has the responsibility of selecting relevant reviewers. We try to solicit comments from two reviewers, but to achieve agreement from two individuals to review a manuscript will typically require that five, and sometimes ten, or even more, individuals are asked to take on the task. Some of these simply do not reply. Others will turn down the request. There may be legitimate reasons for doing so, but on many occasions I am sure that individuals just do not want to engage with the peer-review system, even though they expect others to do so. Nevertheless, Editorial Board members attempt to identify two willing reviewers once they have a manuscript assigned to them and I have an agreement with members of the Editorial Board that they undertake this task in a timely manner. Then comes the stage of the process that is outside of my control: the preparation of the report by the reviewers. If this does not appear within 3 weeks of the assignment, the reviewer is chased up; sometimes this works and sometimes it doesn't. If not, this may lead to a further round of identifying a new reviewer, or a decision may be made to proceed with only one reviewer's report. When reviewers' reports are received these go to the member of the Editorial Board who has been assigned the manuscript. They will then read the manuscript and the reviewers' reports and prepare their own report. Again, I have an agreement with members of the Editorial Board that they undertake this task in a timely manner. Finally, once the reports of the reviewers and of the Editorial Board member are completed these go to myself or one of the Deputy Editors. They read the manuscript and all of the reports and make a decision. This last process should be completed within days of receipt of the reports. Thus, the processes over which I have direct control (the initial paper handling by the office staff, the assignment of reviewers, and the actions of members of the Editorial Board and of the decision makers) probably take 3 weeks for the average manuscript. Since reviewers are asked to provide their reports within 3 weeks, the average manuscript should take about 6 weeks from receipt to making the decision. In fact, this time for the average manuscript is about 9 weeks. The difference in these times is because potential reviewers do not agree to take on the task or, when they do agree, they do not fulfil the task by the deadline that is requested.

I have attempted to estimate the extent of the total peerreviewing task that is required in the field of nutritional science in any 1 year. In 2007 the $B J N$ received about 875 manuscripts. If each of these was reviewed by two reviewers, this would have resulted in 1750 'peer review episodes'. In 2007 the fifty-six journals in the Nutrition and Dietetics category of ISI Web of Knowledge published 7026 papers. This does not represent all of the papers published in the area of nutritional science in 2007: the Nutrition and Dietetics category does not include some nutrition journals (for example, Journal of Parenteral and Enteral Nutrition); some nutrition journals are not listed at all in the ISI Web of Knowledge; the separate ISI Web of Knowledge category of Food Science and Technology published 12981 papers in 2007, many of these highly relevant to nutritional science; many nutrition studies in wild or domesticated animals, fish, birds and insects are published in journals in categories other than Nutrition and Dietetics and Food Science and Technology; many nutrition and metabolic studies of clinical relevance are published in journals in various medical categories; many mechanistic studies are published in journals 
in biochemistry, molecular biology and physiology categories; and so on. I do not know how many 'nutrition' papers are published in journals not listed in the Nutrition and Dietetics category, but let's estimate this at another 6000 papers from the Food Science and Technology category (i.e. half of the papers published in that category) and another 7000 papers from all the other categories. Thus, in 2007 I roughly estimate that 20000 papers were published in the area of nutritional science. The exact number does not really matter for my argument - it could be as few as 10000 (although I think this estimate is too low) or as many as 30000 . So let me stick with 20000 . If each of these papers was peer reviewed by two reviewers at first submission, this would amount to 40000 'peer review episodes'. Let's say that only $30 \%$ of these papers were accepted by the journal to which they were first submitted. Thus, 14000 manuscripts would have been submitted to a second journal. If each of these new submissions required two peer reviewers, this would amount to a further 28000 'peer review episodes'. Again, let's say that $50 \%$ of these manuscripts were accepted by the second journal. This would leave 7000 manuscripts to be submitted to a third journal resulting in a further 14000 'peer review episodes'. And so on ...... According to these rough assumptions, you will see that in 2007 at least 80000 'peer review episodes' were required to support the publications in our discipline. I may have overestimated and the figure may be as low as 40000 or I may have underestimated it and it could be as high as 160000 . Whatever the exact figure is, it is a huge number!

Making the above estimate has made me think more about the importance of the peer-review process to the service the $B J N$ offers its potential authors. I want the $B J N$ to offer submitting authors an efficient service as far as reaching a decision on a submitted manuscript is concerned; essentially this means shortening the time taken. As you will see from the above considerations the most effective way to achieve this is for the nutritional science community to engage more fully with the process of peer review and once engaged to respond efficiently with thorough and useful reports. Many see peer review as a chore to be avoided if possible - I know this from speaking to colleagues (who incidentally expect their own manuscripts to be peer reviewed in quick time!). This should not be the case. First, participation in peer review is part of an academic's professional responsibilities - it should be seen as a service to the discipline and one of the most important steps in maintaining standards and assuring scientific advancement. Secondly, participation in peer review is an honour and a privilege; the peer reviewer is one of the first to see new data and new interpretations, and their constructive criticism is welcomed by authors since that serves to improve their thinking, their manuscript, and the way that they will go about their future experiments. Those who choose not to engage in peer review when they are both able and capable of doing so are not meeting one of their professional responsibilities, are doing the discipline a disservice, and are not treating their peers with the respect that they deserve. With ever-increasing numbers of manuscripts being submitted to ever-increasing numbers of journals, all requiring peer review, I worry that the inability to identify peer reviewers who will take on the task and who will respond as required to, will undermine the efficiency of publishing and will reverse many of the improvements (in terms of times required for various stages of the publishing process) that have occurred as a result of the use of electronic systems. So next time you receive a request to act as a reviewer, please remember that participating in peer review is both a privilege and a professional duty; by agreeing to take on this task you will be making a valuable contribution to your discipline.

Philip C. Calder

Editor-in-Chief Institute of Human Nutrition School of Medicine University of Southampton IDS Building MP887 Southampton General Hospital Southampton SO16 6YD

$U K$ email pcc@soton.ac.uk

doi:10.1017/S0007114509289070 